\title{
Sound preconditioning therapy inhibits ototoxic hearing loss in mice
}

\author{
Soumen Roy, Matthew M. Ryals, Astrid Botty Van den Bruele, \\ Tracy S. Fitzgerald, and Lisa L. Cunningham
}

National Institute on Deafness and Other Communication Disorders (NIDCD), NIH, Rockville, Maryland, USA.

\begin{abstract}
Therapeutic drugs with ototoxic side effects cause significant hearing loss for thousands of patients annually. Two major classes of ototoxic drugs are cisplatin and the aminoglycoside antibiotics, both of which are toxic to mechanosensory hair cells, the receptor cells of the inner ear. A critical need exists for therapies that protect the inner ear without inhibiting the therapeutic efficacy of these drugs. The induction of heat shock proteins (HSPs) inhibits both aminoglycoside- and cisplatin-induced hair cell death and hearing loss. We hypothesized that exposure to sound that is titrated to stress the inner ear without causing permanent damage would induce HSPs in the cochlea and inhibit ototoxic drug-induced hearing loss. We developed a sound exposure protocol that induces HSPs without causing permanent hearing loss. We used this protocol in conjunction with a newly developed mouse model of cisplatin ototoxicity and found that preconditioning mouse inner ears with sound has a robust protective effect against cisplatin-induced hearing loss and hair cell death. Sound therapy also provided protection against aminoglycoside-induced hearing loss. These data indicate that sound preconditioning protects against both classes of ototoxic drugs, and they suggest that sound therapy holds promise for preventing hearing loss in patients receiving these drugs.
\end{abstract}

\section{Introduction}

Our goal is to develop a clinical therapy that inhibits hearing loss in patients receiving ototoxic drugs. Heat shock protein (HSP) induction is a critical stress response in the inner ear that can promote survival of hair cells exposed to both classes of ototoxic drugs (1-5). Given that HSP induction is a ubiquitous response to stress (6), we hypothesized that sound that is loud enough to stress the inner ear without causing permanent damage would induce HSPs and inhibit ototoxic drug-induced hearing loss.

\section{Results and Discussion}

We developed a sound exposure paradigm that induces HSPs in the mouse cochlea without causing permanent hearing loss. Our goal was to optimize the sound such that it causes a temporary threshold shift (TTS), an indicator that the cochlea is stressed by the sound, but does not produce a permanent threshold shift (PTS). Mice were exposed to an octave band $(8-16 \mathrm{kHz})$ of sound at $90.1 \pm 2.7 \mathrm{~dB}$ sound pressure level (SPL) for 2 hours. Hearing sensitivity was tested by auditory brainstem response (ABR) measurements before sound exposure and again 24 hours and 1 week later. Twenty-four hours after sound exposure, mice had mean threshold shifts (hearing loss) of 9 to $22 \mathrm{~dB}$ (Figure 1A). One week later, hearing sensitivity had recovered to preexposure levels at all frequencies (Figure 1A).

Sound exposure that does not result in PTS may still cause damage to the inner ear, including loss of afferent nerve terminals (7). This subtle damage is reflected in the ABR as a reduction in the amplitude of ABR wave I (7). We measured wave I amplitudes in mice that had undergone sound exposure 5 times over 12 days (see Methods). Wave I amplitudes were measured prior to the first sound exposure and again 3 weeks after the final sound exposure.

Authorship note: Soumen Roy and Matthew M. Ryals are co-senior authors and contributed equally to this work.

Conflict of interest: The authors have declared that no conflict of interest exists. Citation for this article: J Clin Invest. 2013;123(11):4945-4949. doi:10.1172/JCI71353.
There was no change in wave I amplitude between the pretest and post-test ABRs at any frequency (Figure 1B), suggesting that sound exposure resulted in no detectable damage to the auditory system.

We next examined the induction of Hsp mRNA in response to sound exposure. Preconditioning sound induced both Hsp32 (also called heme oxygenase 1, HMOX1, or HO-1) and Hsp70 mRNA expression (Figure 1C). Sound-induced Hsp70 mRNA induction was restricted to the cochlea and was not observed in other organs in sound-exposed mice (Figure 1D).

Studies of cisplatin ototoxicity have been hindered by the lack of suitable mouse models of cisplatin-induced hearing loss (8). Previous models relied on a single injection of high-dose cisplatin, resulting in high toxicity and little reduction in hearing sensitivity (8-10). We developed a new mouse model of cisplatin ototoxicity that approximates the pattern of multiple cycles of cisplatin administration in humans (11-13). We evaluated two cisplatin administration protocols. In the " $4 \times 4$ protocol," mice received cisplatin ( $4 \mathrm{mg} / \mathrm{kg})$ each day for 4 days. The 4 -day cisplatin administration period was followed by 10 days of recovery. This protocol was repeated two additional times for a total of three cycles of cisplatin administration (4 days) followed by recovery (10 days). The " $8 \times 2$ protocol" was similar except that the mice received $8 \mathrm{mg} / \mathrm{kg}$ of cisplatin each day for 2 days per cycle for the same cumulative cisplatin dose. Mice underwent hearing testing prior to the onset of cisplatin administration and again 15 days after the final cisplatin injection. Each protocol caused significant hearing loss (Figure 2A). Cisplatin also caused a severe reduction in distortion-product otoacoustic emissions (DPOAEs), a measure of outer hair cell function (Figure $2 \mathrm{~B}$ ). Since the $4 \times 4$ protocol caused significantly less weight loss than the $8 \times 2$ protocol (data not shown), this protocol was selected for subsequent experiments.

To determine whether sound protects against cisplatin-induced hearing loss, mice were treated with the $4 \times 4$ cisplatin protocol with or without sound preconditioning. The cisplatin administration and sound exposure procedures are schematized in Figure 2C. Mice 
A

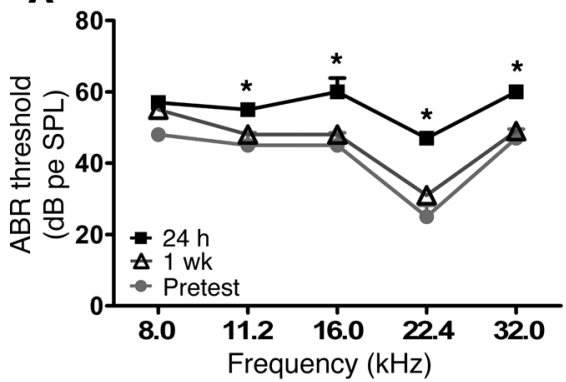

C

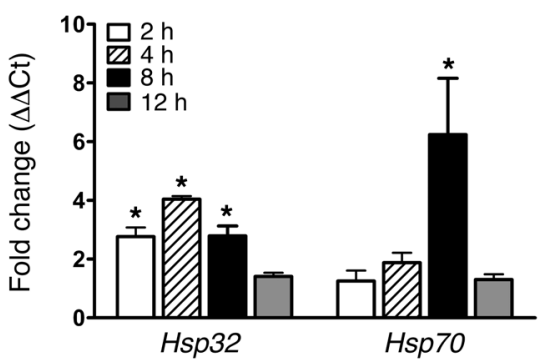

B

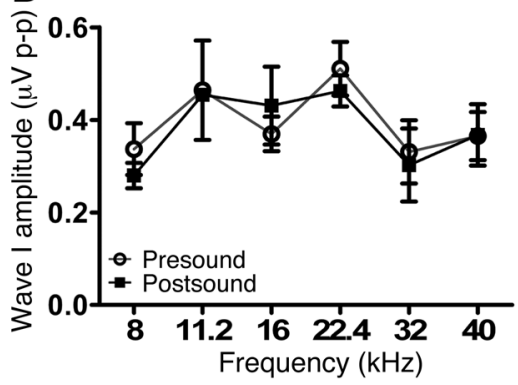

D

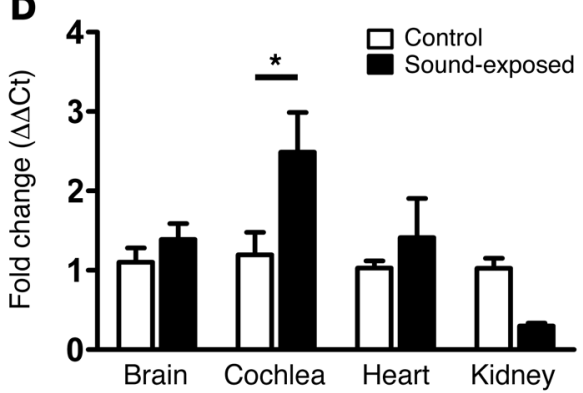

Figure 1

Sound preconditioning induces HSPs without causing permanent hearing loss. Mice were exposed to sound preconditioning (8-16 kHz octave band of noise at $90 \mathrm{~dB}$ SPL) for 2 hours. (A) Hearing thresholds were measured by ABR. Twenty-four hours after sound exposure, mice had mean TTSs of 9 to $22 \mathrm{~dB}$. Hearing sensitivity returned to pretest levels by 1 week after sound exposure. Asterisks indicate significance between the pretest and 24-hour post-test ABR thresholds (ANOVA, ${ }^{*} P<0.05$ ). (B) Sound exposure did not cause any change in the amplitude of ABR wave I. (C) Cochleas from sound-treated and control mice were collected at 2, 4, 8, and 12 hours after sound exposure. Sound caused the induction of $H s p 32$ and $H s p 70$ mRNA in cochleas of sound-treated mice relative to those of untreated (control) mice. Asterisks indicate a significant increase in $H s p$ mRNA relative to control. (D) $\mathrm{Hsp70}$ induction in response to sound was restricted to the cochlea. Tissues were collected from control and sound-exposed mice 8 hours after sound exposure. Sound exposure induced $H s p 70$ mRNA in cochlea but not in brain, heart, or kidney. Asterisk indicates a significant increase in Hsp70 mRNA relative to control. Data shown are the means \pm SEM.

that received sound in addition to cisplatin were exposed to sound on days $1,3,10,14,16,23$, and 28 . Mice that received cisplatin without preconditioning sound had moderately severe threshold shifts across frequencies (Figure 2D). Preconditioning sound resulted in significant protection against cisplatin-induced hearing loss (Figure 2D). The protective effect was greatest at $16 \mathrm{kHz}$, a frequency that was included in the octave sound band, suggesting that the protective effect of sound may be mediated by local effects within the tonotopic (place-frequency) organization of the cochlea.

We analyzed the effect of sound exposure on cisplatin-induced hair cell death. Cisplatin caused extensive loss of outer hair cells in the middle and basal turns (Figure 2, E and F), regions that correspond to the mid- to high-frequency threshold shifts observed by ABR (Figure 2D). Sound inhibited outer hair cell loss in the middle turn, but not in the basal turn (Figure 2, E and F). Together, these data indicate that sound preconditioning protects against hearing loss and outer hair cell death caused by cisplatin.

We next examined whether sound protects against hearing loss caused by the other major class of ototoxic drugs, the aminoglycoside antibiotics. Mice were treated with kanamycin $(750 \mathrm{mg} / \mathrm{kg}$ s.c.) twice daily for 17 days and then allowed to recover for an additional 3 weeks $(2,4,14)$. During the kanamycin administration period, mice were treated with sound every 2.5 days (Figure $3 \mathrm{~A}$ ).
Kanamycin caused moderate-to-severe hearing loss (Figure 3B). Sound exposure resulted in partial protection against kanamycin-induced hearing loss (Figure 3B). Sound also inhibited kanamycin-induced hair cell death (Figure 3C). These data indicate that sound provided modest but significant protection against kanamycin ototoxicity.

Our data indicate that sound preconditioning inhibits hearing loss caused by both major classes of ototoxic drugs, and they suggest that sound therapy holds promise as a strategy for protecting the hearing of patients receiving these drugs. Sound therapy has advantages over other potential protective therapies. First, sound therapy is noninvasive. Second, unlike therapies that use systemic administration of otoprotective drugs, the effects of sound therapy are likely to be restricted to the ear. A major requirement of any therapy aimed at inhibiting ototoxic drug-induced hearing loss is that the proposed therapy must not alter the therapeutic efficacy of the primary drug (i.e., the antineoplastic activity of cisplatin or the antimicrobial activity of the aminoglycosides). Some proposed therapies use systemic antioxidants to protect the inner ear. However, the use of supplemental antioxidants in patients undergoing cancer treatment is controversial $(15,16)$. Because the effects of sound therapy are likely to be restricted to the ear, it is less likely to inhibit the therapeutic efficacy of cisplatin.

Preconditioning sound is also protective against both noise trauma and age-related hearing loss (17-19). The protective effect of conditioning sound is a robust response that has been demonstrated in several species $(17,19,20)$, including humans (21). Previous studies have suggested roles for both glucocorticoid receptors $(22,23)$ and HSPs $(19,24)$ as mediators of the protective effect of sound conditioning. Adrenalectomy abolishes the protective effect of sound conditioning, and treatment with corticosterone partially restores protection $(22,23)$. Sound conditioning maintains the activity and nuclear localization of the glucocorticoid receptor (22). HSPs play major roles in the glucocorticoid response by regulating the maturation, nuclear localization, and degradation of the glucocorticoid receptor (25). Thus, sound preconditioning may induce a generalized stress response in which a cohort of protective molecules are induced, possibly including glucocorticoids (22), HSPs (19, 24), and/or antioxidants (26).

While the current study does not directly address the mechanism(s) underlying the protective effect of sound therapy, our previous data on the protective effects of HSPs created a framework for the rational design of the sound exposure paradigm. Sound resulted in the induction of $H s p 32$ and $H s p 70$, each of which is protective against ototoxicity in mice (2-5). The mouse genome contains three cytoplasmic inducible $H s p 70$ genes, two of which are ubiquitously 
A
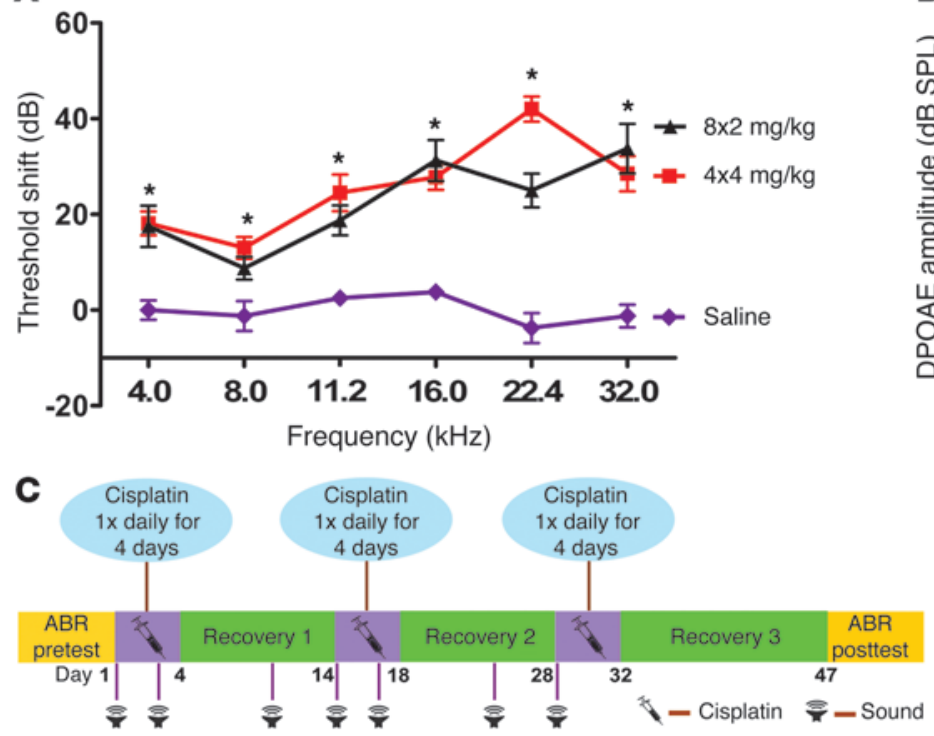

$\mathbf{E}$
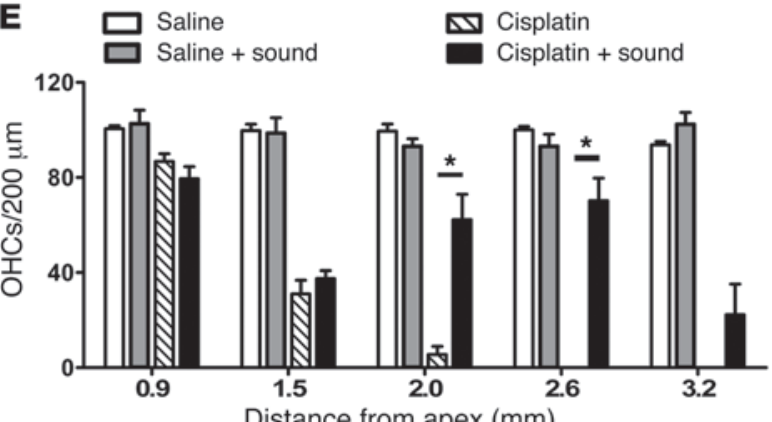

Distance from apex $(\mathrm{mm})$
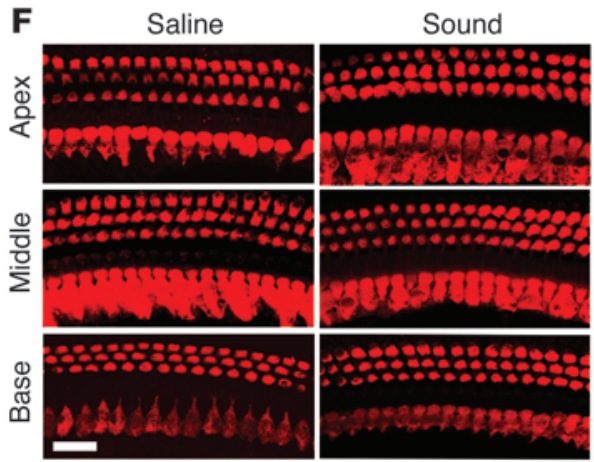

\section{B}

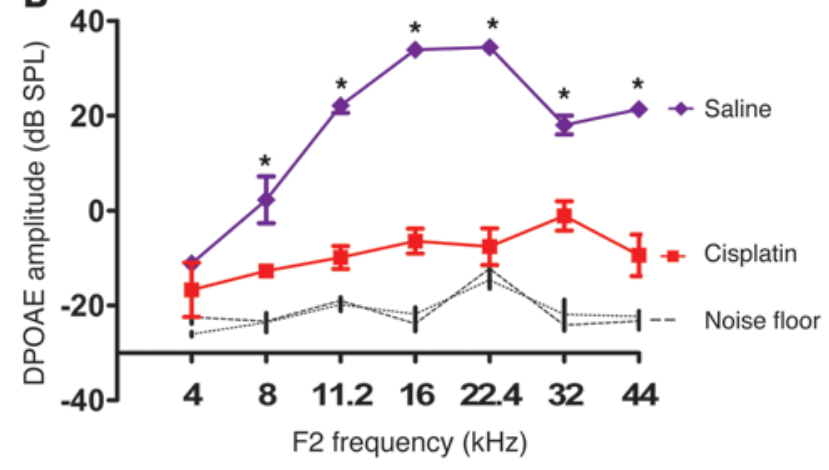

D

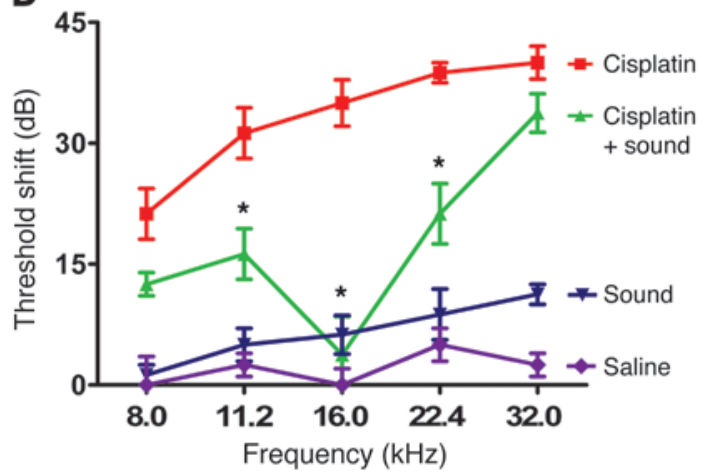

Figure 2

Sound preconditioning protects against cisplatin ototoxicity. (A) Mouse model of cisplatin ototoxicity. Mice underwent three cycles of cisplatin administration consisting of $4 \mathrm{mg} / \mathrm{kg} /$ day for 4 days $(4 \times 4$ protocol) or $8 \mathrm{mg} / \mathrm{kg} /$ day for 2 days $(8 \times 2$ protocol) followed by 10 days of recovery. Hearing was tested by $A B R$ before cisplatin administration and 15 days after the final cycle. Cisplatin caused significant permanent threshold shifts across frequencies (ANOVA, ${ }^{*} P<0.05$, asterisks indicate significance relative to saline-treated mice. Shown are the means \pm SD). (B) Outer hair cell (OHCs) function was examined using DPOAEs. Cisplatin reduced DPOAE amplitudes (ANOVA, ${ }^{*} P<0.05$, asterisk denotes significance relative to the saline-treated mice. Shown are the means \pm SD). (C) Timeline of cisplatin administration and sound exposures. (D) Mice that received cisplatin alone had significant hearing loss at all frequencies relative to mice that received sound alone or saline alone. Sound preconditioning significantly inhibited cisplatin-induced hearing loss (ANOVA, ${ }^{*} P<0.05$, asterisk indicates significance between cisplatin and cisplatin plus sound). (E and F) Cisplatin caused significant loss of OHCs in the upper middle cochlear turn (1.5 mm from the apex) and near-total loss of $\mathrm{OHCs}$ in the middle and basal cochlear turns (2.0-3.2 $\mathrm{mm}$ from the apex). Sound preconditioning significantly improved OHC survival in the middle and the upper basal turns (ANOVA, ${ }^{*} P<0.05$ ). Scale bar: $20 \mu \mathrm{m}$. IHCs, inner hair cells. 


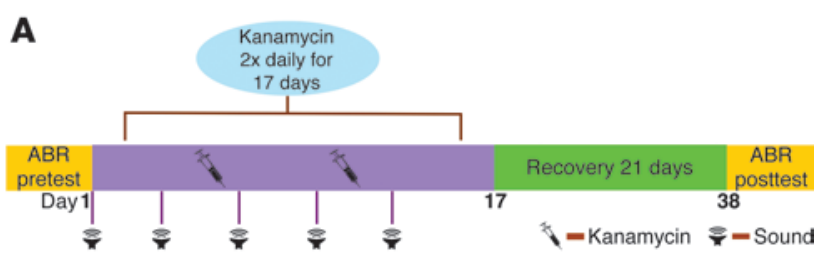

B
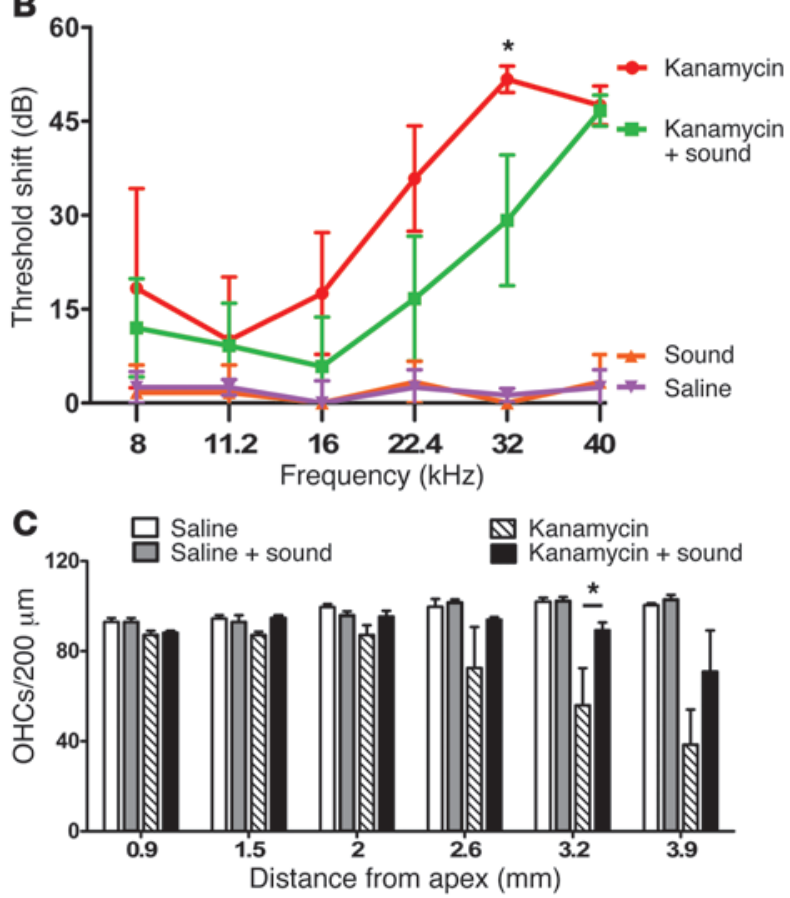

expressed (Hspala and Hspa1b). These two Hsp70 genes are 99\% identical, and their functions appear to be redundant (27). Since our previous data show that HSP32 is also protective (4), a direct test of whether HSPs are required for the protective effect of sound conditioning will require triple-knockout mice (Hspa1a, Hspa1b, and Hmox1). Since these same HSPs are also important safeguards against nephrotoxicity caused by aminoglycosides and cisplatin $(28,29)$, a conditional (ear-specific) triple knockout will be necessary to determine whether HSPs are required for sound-induced protection.

Our data indicate that sound preconditioning inhibits hearing loss caused by both major classes of ototoxic drugs. Given the potential advantages of sound therapy, these data suggest that sound preconditioning holds potential to protect the hearing of patients receiving these drugs.

\section{Methods}

Detailed methods are provided in the Supplemental Methods (supplemental material available online with this article; doi:10.1172/JCI71353DS1).

Animals. CBA/CaJ mice of both sexes were obtained from The Jackson Laboratory.

Hearing testing. Pretest ABR thresholds were measured 24-48 hours prior to the first drug (cisplatin or kanamycin) administration. Post-test ABR thresholds were measured 15 days after the final cisplatin administration or 21 days after the final aminoglycoside administration. Threshold shifts are reported as the difference between pretest and post-test ABR thresholds.

Sound preconditioning. Sound preconditioning consisted of an $8-$ to $16-\mathrm{kHz}$ octave band noise presented for 2 hours. Unanesthetized mice $(n=4-8$ per

\section{Figure 3}

Sound preconditioning protects against aminoglycoside-induced hearing loss and cochlear hair cell death. (A) Schematic diagram illustrating the timeline of kanamycin administration and sound exposures. (B) Mice that received kanamycin had mean PTSs of 10 to $51 \mathrm{~dB}$. Sound preconditioning reduced kanamycin-induced hearing loss, an effect that was significant at $32 \mathrm{kHz}$ (ANOVA, ${ }^{*} P<0.05$ ). (C) Hair cell counts show that sound preconditioning protected hair cells against kanamycin-induced death in the mid-base (3.2 $\mathrm{mm}$ from the apex) portion of the cochlea (ANOVA, ${ }^{*} P<0.05$ ).

group) were placed in a custom cage that is subdivided into four compartments (one mouse per compartment). The cage was placed on a slowly rotating $(2.7 \mathrm{rpm})$ turntable to ensure uniform sound exposure. A loudspeaker was mounted $10 \mathrm{~cm}$ above the cage. On days when mice received both, preconditioning sound was administered 6 hours prior to drug administration. Cisplatin-treated mice underwent sound exposures on days 1, 3, 10, $14,16,23$, and 28. Kanamycin-treated mice underwent sound exposures on days $1,4,7,10$, and 13 . Sound-only mice were exposed to the same sound schedule as the drug-plus-sound mice. Mice in the cisplatin-only (no sound) group were placed in the subdivided cage atop the rotating turntable for 2 hours without sound exposure on the same schedule as the cisplatin-plussound mice to control for the effects of environmental stress.

$4 \times 4$ cisplatin protocol. Mice were prehydrated with 2 to $3 \mathrm{ml}$ of subcutaneous saline (Hospira) 24 hours before the first cisplatin injection and daily each day cisplatin was administered. Mice also received $1-2 \mathrm{ml}$ saline daily for the first 5 days of each recovery period (and as needed thereafter). Cisplatin $(100 \mathrm{mg} / \mathrm{ml}$; PCH PharmaChemie) was administered i.p. at $4 \mathrm{mg} / \mathrm{kg}$ each day for 4 days. Following this 4-day cisplatin injection period, mice recovered for 10 days. This 14-day protocol was repeated twice more for a total of three cycles of cisplatin administration. Mice had an additional $4-5$ days of recovery following the final cisplatin injection before the post-test ABR.

Statistics. Quantitative PCR data were analyzed using unpaired, 2-tailed Student's $t$ tests or Mann-Whitney $U$ tests. All other data were analyzed either by 1-way, 2-way, or repeated-measures ANOVA with Tukey's, Bonferroni's, and Newman-Keuls post-hoc analyses using SPSS statistical software, version 19 (IBM SPSS, Inc.) or GraphPad Prism software, version 5 (GraphPad Software Inc.). SEM values for the mean data are shown on graphs unless otherwise indicated. For all analyses, $P<0.05$ was considered statistically significant.

Study approval. All procedures were approved by the IACUC of the NIDCD.

\section{Acknowledgments}

This work was supported by the NIH/NIDCD Division of Intramural Research (ZIA DC 000079). The authors thank Su-Hua Sha, Mark Warchol, Nicole Schmitt, and Tiffany Baker for their insightful discussions about mouse models of cisplatin ototoxicity. We are indebted to Donnie Catts and the NIDCD veterinary staff for their excellent animal care. Our thanks to Dennis Drayna, Thomas Friedman, Andrew Griffith, and Carter VanWaes for their helpful comments on the manuscript.

Received for publication May 31, 2013, and accepted in revised form August 12, 2013.

Address correspondence to: Lisa L. Cunningham, National Institute on Deafness and Other Communication Disorders, NIH, 5 Research Ct., Rockville, Maryland 20850, USA. Phone: 301.443.2766; Fax: 301.402.7580; E-mail: Lisa.cunningham@nih.gov. 
1. Cunningham LL, Brandon CS. Heat shock inhibits both aminoglycoside- and cisplatin-induced sensory hair cell death. J Assoc Res Otolaryngol. 2006; 7(3):299-307.

2. Taleb M, Brandon CS, Lee FS, Harris KC, Dillmann WH, Cunningham LL. Hsp70 inhibits aminoglycoside-induced hearing loss and cochlear hair cell death. Cell Stress Chaperones. 2009;14(4):427-437.

3. Taleb M, Brandon CS, Lee FS, Lomax MI, Dillmann WH, Cunningham LL. Hsp70 inhibits aminoglycoside-induced hair cell death and is necessary for the protective effect of heat shock. J Assoc Res Otolaryngol. 2008;9(3):277-289.

4. Francis SP, Kramarenko II, Brandon CS, Lee FS, Baker TG, Cunningham LL. Celastrol inhibits aminoglycoside-induced ototoxicity via heat shock protein 32. Cell Death Dis. 2011;2:e195.

5. May LA, et al. Inner ear supporting cells protect hair cells by secreting HSP70. J Clin Invest. 2013; 123(8):3577-3587.

6. Martindale JL, Holbrook NJ. Cellular response to oxidative stress: signaling for suicide and survival. J Cell Physiol. 2002;192(1):1-15.

7. Kujawa SG, Liberman MC. Adding insult to injury: cochlear nerve degeneration after "temporary" noise-induced hearing loss. J Neurosci. 2009; 29(45):14077-14085.

8. Poirrier AL, et al. Ototoxic drugs: difference in sensitivity between mice and guinea pigs. Toxicol Lett. 2010;193(1):41-49.

9. More SS, Akil O, Ianculescu AG, Geier EG, Lustig LR, Giacomini KM. Role of the copper transporter, CTR1, in platinum-induced ototoxicity. J Neurosci. 2010;30(28):9500-9509.

10. Hill GW, Morest DK, Parham K. Cisplatin-induced ototoxicity: effect of intratympanic dexamethasone injections. Otol Neurotol. 2008;29(7):1005-1011.

11. Minami SB, Sha SH, Schacht J. Antioxidant protection in a new animal model of cisplatin-induced ototoxicity. Hear Res. 2004;198(1-2):137-143.

12. Martins RG, et al. Cisplatin and radiotherapy with or without erlotinib in locally advanced squamous cell carcinoma of the head and neck: a randomized phase II trial. J Clin Oncol. 2013;31(11):1415-1421.

13. Holtz DO, Dunton CJ. Chemotherapy: cisplatin combinations in cervical cancer-which is best? Nat Rev Clin Oncol. 2010;7(2):74-75.

14. Wu WJ, Sha SH, McLaren JD, Kawamoto K, Raphael $\mathrm{Y}$, Schacht J. Aminoglycoside ototoxicity in adult CBA, C57BL and BALB mice and the Sprague-Dawley rat. Hear Res. 2001;158(1-2):165-178.

15. Lawenda BD, Kelly KM, Ladas EJ, Sagar SM, Vickers A, Blumberg JB. Should supplemental antioxidant administration be avoided during chemotherapy and radiation therapy? J Natl Cancer Inst. 2008; 100(11):773-783

16. Block KI, Koch AC, Mead MN, Tothy PK, Newman RA, Gyllenhaal C. Impact of antioxidant supplementation on chemotherapeutic toxicity: a systematic review of the evidence from randomized controlled trials. Int J Cancer. 2008; 123(6):1227-1239.

17. Canlon B, Fransson A. Morphological and functional preservation of the outer hair cells from noise trauma by sound conditioning. Hear Res. 1995; 84(1-2):112-124.

18. Tanaka C, Bielefeld EC, Chen GD, Li M, Henderson D. Ameliorative effects of an augmented acoustic environment on age-related hearing loss in middle-aged Fischer 344/NHsd rats. Laryngoscope. 2009; 119(7):1374-1379.

19. Yoshida N, Liberman MC. Sound conditioning reduces noise-induced permanent threshold shift in mice. Hear Res. 2000;148(1-2):213-219.

20. Pukkila M, Zhai S, Virkkala J, Pirvola U, Ylikoski J. The "toughening" phenomenon in rat's auditory organ. Acta Otolaryngol Suppl. 1997;529:59-62.

21. Miyakita T, Hellstrom PA, Frimanson E, Axelsson A. Effect of low level acoustic stimulation on temporary threshold shift in young humans. Hear Res. 1992;60(2):149-155.

22. Meltser I, Canlon B. Protecting the auditory system with glucocorticoids. Hear Res. 2011;281(1-2):47-55.

23. Tahera Y, Meltser I, Johansson P, Salman H, Canlon $B$. Sound conditioning protects hearing by activating the hypothalamic-pituitary-adrenal axis. Neurobiol Dis. 2007;25(1):189-197.

24. Yoshida N, Kristiansen A, Liberman MC. Heat stress and protection from permanent acoustic injury in mice. J Neurosci. 1999;19(22):10116-10124.

25. Grad I, Picard D. The glucocorticoid responses are shaped by molecular chaperones. Mol Cell Endocrinol. 2007;275(1-2):2-12

26. Jacono AA, Hu B, Kopke RD, Henderson D, Van De Water TR, Steinman HM. Changes in cochlear antioxidant enzyme activity after sound conditioning and noise exposure in the chinchilla. Hear Res. 1998; 117(1-2):31-38

27. Hunt CR, et al. Genomic instability and enhanced radiosensitivity in Hsp70.1- and Hsp70.3-deficient mice. Mol Cell Biol. 2004;24(2):899-911.

28. Zhou H, Kato A, Yasuda H, Odamaki M, Itoh $H$, Hishida A. The induction of heat shock protein-72 attenuates cisplatin-induced acute renal failure in rats. Pflugers Arch. 2003;446(1):116-124.

29. Kim J, et al. In vivo regulation of the heme oxygenase-1 gene in humanized transgenic mice. Kidney Int. 2012;82(3):278-291. 